\title{
Erectile dysfunction guideline: A missed opportunity?
}

\author{
Gerald B. Brock, MD, FRCSC'; Faysal A. Yafi, MD, FRCSC ${ }^{2}$ \\ 'Professor Emeritus, Western University, London, ON, Canada; ${ }^{2}$ Department of Urology, University of California Irvine, Irvine, CA, United States
}

Cite as: Brock GB, Yafi FA. Erectile dysfunction guideline: A missed opportunity? Can Urol Assoc J 2021;15(10):323. http://dx.doi.org/10.5489/cuaj.7593

See related guideline on page 310

$\amalg$ rectile dysfunction (ED) management was transformed more than two decades ago, following the approval and widespread use of effective oral agents. Despite great strides having been achieved in therapeutics, management and case-finding strategies that can promote better sexual health and satisfaction within the Canadian population remain elusive. Only a minority of men are asked about their sexual health by their treating physician, and well-established links between ED and cardiovascular disease (CVD) and lower urinary tract symptoms (LUTS) remain largely unrecognized by many primary care givers and urologists. The utility of a well-written, evidence-based, contemporary guideline providing management advice and addressing the important unresolved questions on ED evaluation and treatment that exist for Canadian physicians is, in our opinion, timely and needed.

The authors of the Canadian Urological Association guideline have produced a thorough summary of the condition. ${ }^{1}$ The management approach algorithm they propose is reasonable and in keeping with most other guidelines - apart from the lack of clear guidance on the role of testosterone as a potential reversible cause and the evolving evidence for a potential role of regenerative therapies, such as low-intensity shockwave therapy in selected patients with vasculogenic ED (included in the 2021 European Association of Urology guidelines). ${ }^{2}$

In this scholarly manuscript, the authors have used a methodology that produced a series of five questions, to which they provided evidence-based responses. While we are clearly not methodologists, we have published over 300 peer-reviewed scientific articles related to sexual health, have been active in the field for many years, have vast experience running large tertiary care clinical practices for men with ED, and have delivered hundreds of peer lectures on the subject to urologists, primary physicians, specialists, and the public. In our opinion, based on these encounters with hundreds of physicians over many years, the major shortcomings were: the five key guideline questions addressed, their lack of strong evidence, and the inability of the guideline writing group to arrive at clinical recommendations, which unfortunately dilutes this guideline's utility to a certain extent.

The guideline provides an evidence-based consensus in the narrative portion of the manuscript, which is fair and balanced. However, we find it surprising that they chose the questions they did, which form a major portion of the document. Unfortunately, all the questions they addressed had insufficient evidence, based on their criteria, to arrive at clinical guidance. It is our understanding that this is the underlying rationale for publishing a guideline: to critically review the highest available level of evidence to help steer clinical management from a panel of experts, providing the readership with their integration of the data with clinical expertise. In the absence of evidence of sufficient strength, a consensus statement based on expert opinion may have added to the value of this report and helped guide clinicians.

In addition, we would have thought it of value to address other key and evolving clinical controversies in men's sexual health, such as: the role and safety of testosterone in men with ED, the relationship of ED with LUTS and CVD, management of concomitant Peyronie's disease, and given that this is intended to be a urology guideline, a section on surgical management - addressing questions on informed consent, the type of implant that is optimal, risks for various patient groups, and long-term outcomes - would have enhanced this document.

Competing interests: Dr. Brock has been an advisory board member for and holds investments in Boston Scientific. Dr. Yafi has been a consultant/speaker for Acerus, Antares Pharma, Clarus Therapeutics, Coloplast, and Cynosure; an advisory board member for Coloplast, Cynosure, and Promescent; and received a research grant from Viome.

\section{References}

1. Domes T, Najafabadi BT, Roberts M, et al. Canadian Urological Association guideline: Erectile dysfunction. Can Urol Assoc J 2021;15:310-22. http://dx.doi.org/10.5489/cuaj.7572

2. Salonia A, Bettocchi C, Boeri L, et al; EAU Working Group on Male Sexual and Reproductive Health. European Association of Urology guidelines on sexual and reproductive health — 2021 update: Male sexual dysfunction. Eur Urol 2021;80:333-57. htrps://doi.org/10.1016/i.eururo.2021.06.007

Correspondence: Dr. Gerald B. Brock, Western University, London, 0N, Canada; gebrock88@gmail.com 